Philosophia Reformata 63 (1998) 62-69

\title{
DE DEMOCRATISCHE REGHTSSTAAT AAN HET EINDE VAN DE GESCHIEDENIS. EEN REACTIE OP KEES KLOP
}

\section{P.B. Cliteur}

De redactie van Philosophia Reformata heeft een belangrijk project opgezet. Aan de schrijvers van het boek van de Open Universiteit waaraan vertegenwoordigers van verschillende levensbeschouwelijke richtingen hebben meegewerkt, is de mogelijkheid geboden met elkaar in dialoog te treden. De bijdrage van Kees Klop biedt daarvoor om verschillende redenen een uitstekende basis. Ik heb het getroffen met een commentator die de lijn van mijn verhaal voortreffelijk heeft samengevat. We behoeven dus geen tijd te verdoen met het rechtzetten van misverstanden, iets dat doorgaans een belangrijk onderdeel vormt van reacties. Ik vlei mij een beetje met de gedachte dat Klops sympathieke weergave van de essentie van mijn betoog ook wellicht daarom zo goed geslaagd is, omdat wij putten uit ten dele verwant gedachtengoed. Ik ben namelijk, net als Klop, onder de indruk van het werk van Dooyeweerd. Dat gaat terug op de tijd dat ik als student-assistent verbonden was aan de afdeling Encyclopedie van de rechtswetenschap van de VU bij Prof. H.J. van Eikema Hommes. Laatstgenoemde was, zoals de lezers van Philosophia Reformata bekend is, een leerling van Dooyeweerd.

Kennismaking met het werk van Dooyeweerd is overigens voor een jurist niet zonder gevaren. Men raakt op zodanige wijze "gedeformeerd" dat men gemakkelijk onvrede blijft houden met de dominante wijze van staatsrechtbeoefening, een traditie waaraan door een andere grootheid uit kringen van de VU een belangrijke bijdrage is geleverd: A.M. Donner. De staatsrechtgeleerde Couwenberg heeft-terecht-de visie van Donner wel eens getypeerd als "theoretisch agnosticisme". ${ }^{1}$ Donner had een broertje

1. Couwenberg, S.W., De omstreden staat. Ontwikkeling en problematiek van de staatstheorie in de 20ste eeuw, Samsom, Alphen aan den Rijn 1974, $p$. 48. Couwenberg spreekt van het "vermoeid scepticisme" van Donner en hij noemt diens fundering van gezag en recht "onzeker en weinig duidelijk" Over het door Donner bewerkte handboek van Van der Pot schrijft Couwenberg dat daarin "een klare, consistente conceptie moeilijk te vinden valt". Kenmerkend voor Donner is een "theoretisch agnosticisme". Dat lijken 
dood aan systematische filosofische reflexie, zoals in het werk van Dooyeweerd nu juist zo uitvoerig te vinden was. Helaas is de traditie van Donner van oudsher dominant in Nederland en zij is dat gebleven tot op de dag van vandaag. Dat het staatsrechtelijk denken van Dooyeweerd in Nederland weinig weerklank heeft gevonden was overigens niet alleen de "verdienste" van Donner, maar is ook te verklaren uit de pragmatische benadering die in het Nederlandse staatsrecht sinds onze grondwetten aan het begin van de vorige eeuw gebruikelijk is geweest. De koning benoemde op op 21 december 1813 een staatscommissie. Deze bestond uit 14 en later 15 leden die een ontwerp voor een grondwet moest maken. Gijsbert Karel van Hogendorp had reeds een schets voor een constitutie gemaakt die tot uitgangspunt werd genomen. Die schets was al in 1812 door Van Hogendorp opgesteld, omdat hij voorzien had dat het Franse bewind niet lang stand zou houden.

De grondwet van Van Hogendorp onderscheidde zich van die van 1798 doordat hij niet op een staatstheoretische grondslag was gevormd. De leer der theorieën heeft ons ongelukkig gemaakt, zo stelt Van Hogendorp in de eerste vergadering van de grondwetscommissie. "Wij moeten tot ondervinding terugkeren".2

Hoe paradoxaal ook, de staatsrechtbeoefening van Dooyeweerd en zijn leerlingen Van Eikema Hommes en Mekkes lijkt meer op het staatsrecht van de revolutionaire periode die aan de periode van het theoretisch agnosticisme voorafging, dan op het pragmatisme van Van Hogendorp en Donner.

De dominante staatsrechtswetenschap in Nederland zou men "waarden-blind" kunnen noemen. Dat komt onder andere tot uitdrukking in het gegeven dat van het belangrijkste begrip van het staatsrecht men geen helder beeld heeft kunnen krijgen. ${ }^{3}$ Het

arde typeringen voor een groot staatsrechtsgeleerde. Maar wanneer men oed let op wat Couwenberg hier aan de orde stelt (het gebrek aan doorlenking van de grondslagen van het staatsrecht) dan blijkt zijn typering toch rel juist.

2 Aangehaald bij: Gerbenson, P., \& Algra, N.E., Voortgangh des rechtes. De intwikkeling van het Nederlandse recht tegen de achtergrond van de Westuropese cultuur, 6e druk, Samsom H.D. Tjeenk Willink, Alphen aan den ijn 1987, p. 219. Vgl, ook J. De Bosch Kemper, De grondwettige regten der volkslertegenwoordiging ten opzigte van de ministeriële verantwoordelijhheid. Naar aaneiding van de laatste opstellen van Prof. Opzoomer en Vissering, E.S. Witamp, Amsterdam 1866, p. 4: "De onstuimige partijen hebben vóór 1795 de tationaliteit ondermijnd en de Fransche heerschappij voorbereid".

3 Een goed boek als dat van Dooyeweerd's leerling Mekkes, J.P.A., Proeve 'ener critische beschouwing van de ontwikkeling der humanistische rechtsstaatstheorieën, 
centrale begrip van het staatsrecht is de democratische rechtsstaat. ${ }^{4}$ Op de vraag "wat is Nederland in constitutioneel opzicht?" luidt het antwoord: "Nederland is een democratische rechtsstaat". Voor elke staatsrechtelijke vraag die men wil oppakken geldt dat wanneer men niet weet waarop dat staatsrecht gericht is (de "rechtsidee"), dat wil zeggen: welk ideaal het moet dienen, elke analyse gebrekkig en onzeker blijft. Neem de volgende vragen. Wat is de positie van het Openbaar Ministerie? Hoe moet men de verhouding zien van koning en ministers? Moeten wij constitutionele toetsing introduceren? Enzovoorts, enzovoorts. Het zijn vragen die men alleen maar kan beantwoorden tegen de achtergrond van een reflexie op het ideaal waarop onze constitutionele orde gericht is. Dooyeweerd begreep dat en hij wijdde dan ook-net als zijn leerlingen-veel zorg aan het omlijnen van het rechtsstaatsbegrip. ${ }^{5}$

Donner had daarvoor weinig tot geen belangstelling. De keren dat hij commentaar heeft moeten geven op de benadering van de "Doctor systematicus" 6 gebeurde dat met grote tegenzin, nauwe-

Libertas drukkerijen, Utrecht/Rotterdam 1940 is in de staatsrechtelijke literatuur bijna volledig genegeerd.

4 Reeds aan het begin van deze eeuw werd erop gewezen dat het niet langer adequaat is het Nederlandse constitutionele bestel in "royalistische" termen te typeren, zoals geschiedt in de aanduiding "constitutionele monarchie". Zo schirijft Van der Pot over Krabbe: "Hij betwistte (...) het goed recht om onzen regeeringsvorm een monarchalen te noemen. Dezelfde reden die verhinderde om een verschil in regeeringsvorm aan te nemen op grond van het al of niet aanwezig zijn van een Raad van State, had ook er van moeten weerhouden om den onze te bepalen door het ambt van een Koning". Vgl. Pot, C.W. van der, De plaats van het koningschap in ons hedendaagsche staatsrecht, Mededelingen der Koninklijke Nederlandsche Akademie van Wetenschappen, Afd. Letterkunde, Nieuwe Reeks, deel 2, nr. 10, N.V. Noord-Hollandsche Uitgeversmaatscahppij, Amsterdam 1939, p. 2. Vgl. tevens: Krabbe, Staatsrechtelijhe Opstellen, 1927, I, p. 90 e.v.

5 In de nieuwe staatsrechtelijke literatuur gebeurt dat ook bij: Zoethout, C.M., Constitutionalisme. Een vergelijkend onderzoek naar het beperken van overheidsmacht door het recht, Gouda Quint, Arnhem 1995; Burkens, M.C., "De Nederlandse rechtsstaat", in: S.W. Couwenberg (red.), Op de grens van twee eeuwen, Positie en perspectief van Nederland in het zicht van het jaar 2000 , Kok Agora, Kampen, in samenwerking met de Stichting Civis Mundi 1989, pp. 87-99 en Burkens, M.C., e.a., Beginselen van de democratische rechtsstaat. Inleiding tot de grondslagen van het Nederlandse staats- en bestuursrecht, W.E.J. Tjeenk Willink, Deventer 1997.

6 Zo werd Dooyeweerd aangeduid door Donner in "Bijdrage tot de discussie over de staatstaak" (1951), in: Rechtsgeleerde opstellen aangeboden aan Prof. dr. Dooyeweerd, ook in: A.M. Donner, Tussen het echle en het gemaakte, W.E.J. Tjeenk Willink, Zwolle 1986, Pp. 61-71. 
lijks verholen irritatie en zonder dat werd ingegaan op het centrale streven van Dooyeweerd: het ontwikkelen van een systematisch goed doordacht begrip van de rechtsstaat. In de bewerking van het standaardwerk op dit terrein, het handboek van Van der Pot, komt het woord "rechtsstaat" eén keer voor. Dat geeft te denken. Donner geeft daarvan een omschrijving die vervolgens aan bijna alle rechtenfaculteiten onderwezen wordt en helaas ook in vele rechtsgeleerde handboeken ingang heeft gevonden. ${ }^{7}$ Deze omschrijving luidt als volgt:

"In de loop van de $19 \mathrm{e}$ eeuw heeft het begrip van de rechtsstaat vaste vorm gekregen in de eisen:

$a$ dat er een grondwet of constitutie zij, welke bindende voorschriften bevat voor de betrekkingen van overheid en burgers, $b$ waarin een scheiding van machten wordt verzekerd, met name (1) wetgeving in overeenstemming met een parlement, (2) een onafhankelijke rechterlijke macht, die niet alleen geschillen tussen de burgers onderling, maar ook die tussen overheid en burger beslist, en (3) een bestuursoptreden dat op de wet berust, $c$ en waardoor grond- of vrijheidsrechten van de burger worden omschreven en gewaarborgd". 8

Donner schrijft niet waar hij deze omschrijving vandaan haalt, noch legt hij enige verantwoording af waarom hij het centrale begrip "rechtsstaat" zo en niet anders omschrijft. De omschrijving roept echter allerlei vragen op. Komen niet de kenmerken a t/m c ook al vóór de negentiende eeuw voor? Hoe verhoudt zich rechtsstaat tot democratie? Voor Donner is het laatste kennelijk een onderdeel van het eerste, maar wáarom? Waarom zou men a $t / m$ c eigenlijk opnemen?

De "methode" waarvan Donner zich bedient bij het omlijnen van het rechtsstaatsbegrip-of liever: de afwezigheid daarvan-zou

7 Ook bij de politiek filosoof Woldring. Vgl. zijn overigens voortreffelijke boek: Woldring, H.E.S., Politieke filosofie. Een systematische inleiding, Aula, Het Spectrum, Utrecht 1993, pp. 130-132 die het begrip van Donner nog verder ontwikkelt in een "niet restrictieve" benadering waarmee hij het concept-naar mijn oordeel althans-belast met allerlei politieke idealen. Dat gebeurt ook in verschillende rapporten van het CDA waar men spreekt van een "sociale rechtsstaat" en hier en daar zelfs van een "sociale ecologische rechtsstaat". (Dat laatste, meen ik mij te herinneren, ook ergens bij Klop). Waarom geen sociale feministische rechtsstaat?

8 Donner, A.M., Handboek van het Nederlandse staatsrecht, oorspronkelijk: C.W. van der Pot, bewerkt door A.M. Donner, $11 \mathrm{e}$ druk, W.E.J. Tjeenk Willink, Zwolle 1983, p. 143. 
men de "verzamelmethode" kunnen noemen. Men kijkt wat in een bepaalde tijd en bij bepaalde auteurs als "rechtsstaat" wordt aangeduid en makkt van die kenmerken dan een eigen selectie. Maar omdat men geen selectiecriterium heeft vastgesteld, wordt in het begrip "rechtsstaat" opgenomen wat door een toevallige verzameling van auteurs als zodanig wordt aangeduid.

Het is eigenlijk dank zij enkele geschriften van het Wetenschappelijk Instituut van het $\mathrm{CDA}^{9}$ en de dissertaties van Klop, Klink, Sap ${ }^{10}$ en Balkenende dat de benadering van Dooyeweerd in de politiek nog enigszins levend is gebleven. De paradox is hier dat een op de praktische politiek gerichte instelling als een wetenschappelijk bureau van een politieke partij, een reflexie op de grondslagen van het staatsrecht beter levend heeft gehouden dan de academische staatsrechtbeoefening. Men mag hopen dat de waarden-blinde en onbevredigende wijze van werken van de dominante staatsrechtwetenschap, een manier van werken waar ook S.W. Couwenberg zijn leven lang tegen te hoop is gelopen, ${ }^{11}$ ooit nog eens zal worden verlaten ten gunste van een systematisch beter doordachte conceptie zoals bijvoorbeeld die van Dooyeweerd.

Tot zover waarover Klop en ik het wellicht eens kunnen zijn. Nu het verschil. Naar mijn idee komt dat reeds duidelijk naar voren direct nadat Klop zijn weergave van mijn artikel heeft afgerond. Ik zou zijn benadering "Erasmiaans" willen noemen en die van mij "Kuyperiaans" (en ook Dooyeweerdiaans). Anders gezegd: ik ga uit van de anti-these tussen het christelijk en het humanistisch grondmotief, ${ }^{12}$ Klop probeert deze twee tradities, net als zijn partij

9 Onder andere: Publieke gerechtigheid. Een christen-democratische visie op de rol van de overheid in de samenleving, Rapport van het Wetenschappelijk Instituut voor het CDA, Bohn Staleu Van Loghum, Houten 1990.

io Veelbelovend voor de ontwikkeling van het staatsrecht is ook het werk van enkele jongere auteurs aan de VU. Vgl. Sap, John W., Decency versus Justice. The Call for Morality in The Netherlands, Van Gorcum, Assen 1997; Hofman, J.A., \& Sap, J.W., \& Sewandono, I., Grondrechten in evenwicht, Kluwer, Deventer 1995 .

11 Ook het werk van Couwenberg is overigens verwant aan dat van Dooyeweerd. Net als Dooyeweerd ziet Couwenberg de ontwikkeling van het westerse staatsrecht sinds de renaissance gekleurd door de dialektiek van macht en vrijheid. Vgl. reeds: Couwenberg, S.W., Democratische rechtsstaat en het emancipatiestreven. Rede uitgesproken bij de aanvaarding van het ambt van gewoon hoogleraar in het staats- en bestuursrecht aan de Erasmus Universiteit Rotterdam op 17 februari 1977, z.p., z.j. en ook nog in: Couwenberg, S.W., Geschiedenis ats noodlot, Kok/Agora, Pelckmans 1995.

12 Uitvoeriger hierover: Cliteur, P.B., "De anti-these opnieuw bezien", in: Christen Democratische Verkenningen, 11, 1994, pp. 464-475. "Onze strijd gaat niet 
het CDA, met elkaar te verzoenen. Men zou de tegenstelling ook als volgt kunnen typeren. De benadering van Klop is "katholiek" (Plato en Aristoteles gekerstend) en die van mij "protestant" (Athene en Jeruzalem zijn toch echt verschillend). In het CDA schrijdt die "katholisering" of Erasmiaanse geest ook steeds verder voort. Van een Christelijk Democratisch Appèl (CDA) ontwikkelt het zich tot een Theïstisch Democratisch Appèl (TDA), waarin ook moslims en joden welkom zijn. En vandaar weer naar een partij waarvan ook agnosten (Zijderveld) en cultuurchristenen lid van kunnen zijn. Kortom, het verschil tussen humanisme en christendom verdampt. ${ }^{13}$

Vandaar ook dat Klop kan spreken van mijn "felle atheïsme". Ik ervaar dat zelf natuurlijk niet als "fel", maar gewoon als doordacht of bewust. Evenmin als het "fel" is om uit te spreken dat ik gemeten aan bepaalde criteria "Nederlander" ben, is het "fel" om uit te spreken dat ik gemeten aan bepaalde criteria geen theïst ben. Mijn atheïsme is ook niet feller dan het theïsme van Kuyper of van Dooyeweerd. Maar vanuit een perspectief waarin levensbeschouwelijke tegenstellingen naar de achtergrond moeten verdwijnen-een dominante tendens in de hedendaagse cultuur waarbij het CDA zich aansluit-wordt dat kennelijk als "fel" ervaren.

En nu waarschuwt mijn computer mij dat ik met 2116 woorden reeds de 2000 woorden heb overschreden die de redactie mij als limiet gesteld heeft. Vliegensvlug besluit ik met enkele punten die ik eigenlijk nog in reactie op Klop had moeten uitwerken, maar die ik nu alleen kan aanstippen.

(i) Hij vraagt zich af hoeveel burgers zich laten leiden door humanistische idealen, een vraag die zich des te sterker opdringt wanneer men bedenkt dat het Humanistisch Verbond slechts 16.000 leden telt. Mijn antwoord: ik spreek over het humanisme als hoofdstroom in de Europese cultuur sinds de renaissance, hetzelfde humanisme dat Dooyeweerd kennelijk voor ogen stond

tegen personen, maar tegen de God in het staatsrecht verzakende geest, die in aller Liberalen politiek zich belichaamt", zei Kuyper in zijn rede Volharden bij het ideaal uit 1901. Vgl. Oud, P.J., Honderd jaren. Een eeuw van staatkundige vormgeving in Nederland 1840-1940, 7e herziene druk, bewerkt door J. Bosmans, Van Gorcum, Assen 1979, p. 177.

13 Vgl. uitvoeriger: Cliteur, P.B., "Op weg naar een Theĩstisch Democratisch Appèl?", in: Christen Democratische Verkenningen, nr, 11, 1997, pp. 572-578. 
toen hij in 1931, dus ruim voor de oprichting van het HV, De crisis der humanistische staatsleer schreef. ${ }^{14}$

(ii) Is het humanistisch grondmotief inderdaad een "religieuze" vooronderstelling? Ja, voorzover men het woord "religieus" hanteert in de etymologische zin. Maar persoonlijk vind ik dat niet erg bevredigend. Het leidt ertoe dat elke niet meer verder te verantwoorden keuze tot een "religieuze" keuze wordt gemaakt. Dit leidt tot inflatoir gebruik van het woord "religieus", een benadering waarop overigens ook de theologie van $\mathrm{H}$. Kuitert gebaseerd is.

(iii) Hoe kan Cliteur de democratische rechtsstaat zo sterk met humanisme in verband brengen wanneer we ook in het oude Griekenland wortels van democratie en rechtsstatelijk denken vinden? Mijn antwoord: omdat ik de renaissance zie als een voortzetting van het klassieke gedachtengoed (re-naissance van wat?) dat in zijn hoofdstroom eveneens als humanistisch valt te typeren. ${ }^{15}$ Ik ga hier dus niet mee met Dooyeweerd. Het humanistisch grondmotief van natuur en vrijheid vinden we ook al in de oudheid (die hij bevangen acht in de dialectiek van vorm en materie).

En nu zit ik op 2500 woorden. Ik moet dus hopen op clementie van de redactie en mij verontschuldigen tegenover Klop, omdat ik niet op al zijn vragen een antwoord heb gegeven. Ik hoop dat de grote lijnen echter duidelijk maken hoe dat antwoord zou hebben kunnen luiden. Hij zal ook begrijpen dat ik een bescheiden protest wil laten horen tegen de suggestie die besloten ligt in zijn laatste drie zinnen. "Iets meer bescheidenheid is daarom op zijn plaats. Het daarmee samenhangende respect (...)".

Moet ik daaruit begrijpen dat mijn bijdrage geen blijk zou geven van bescheidenheid en van respect, omdat ik de rechtsstaatsgedachte innig verbonden acht met wat ik noem "humanistisch" gedachtengoed? Laat ik mijn protest formuleren in de vorm van een vergelijking. Stel ik ben burgemeester van Amsterdam en ik

14 Dooyeweerd, H., De crisis der humanistische staatsleer in het licht eener calvinistische kosmologie en kennistheorie, N.V. Boekhandel W. ten Have, Amsterdam 1931,

15 Vgl. Luce, J.V., An Introduction to Greek Philosophy, Thames and Hudson, London 1992, pp: 79-94 die het optreden van Socrates en de Sofisten behandelt onder de titel "Humanism and Enlightenment". De grote neokantiaanse geschiedschrijver van de filosofie Windelband, W., History of Ancient Philosophy, Translated by Herbert Nernest Cushman, Dover Publications, New York 1956 (Duitse versie 1900), pp. 100-155 doet hetzelfde. 
ontvang een collega uit het buitenland. Dan zou het niet erg bescheiden zijn aan het diner voortdurend de loftrompet van Amsterdam te steken en de stad en cultuur van mijn collega onbesproken te laten. Nu een andere vergelijking. Stel ik ben een academicus, bijvoorbeeld een historicus of een socioloog, die werkt aan een dissertatie over Amsterdam. Toevallig woon ik zelf ook in Amsterdam. In het laatste geval moet ik mijn wetenschappelijke bevindingen niet aanpassen aan wat "bescheidenheid" in een geheel andere context zou gebieden op grond van het feit dat ik zelf toevallig in Amsterdam woon. Anders gezegd: in de wetenschappelijke context mag "bescheidenheid" geen rol spelen, maar telt alleen waartoe mijn onderzoek mij brengt.

Maar nu moet ik dan toch echt sluiten. Ik doe dat met dank aan Klop voor zijn commentaar en aan de redactie van Philosophia Reformata voor het lovenswaardig initiatief de dialoog tussen de levensbeschouwelijke richtingen op deze wijze te hebben bevorderd. Deze bijdrage is in die zin "negatief" dat ik veel heb gezegd hoe het naar mijn idee niet moet. Hoe het-naar mijn idee-wel moet heb ik uitgewerkt in het oorspronkelijke artikel waarop Klop zijn gewaardeerd commentaar heeft gegeven. 